\title{
Reversible coma and Duret hemorrhage after intracranial hypotension from remote lumbar spine surgery: case report
}

\author{
Robert H. Bonow, MD, James W. Bales, MD, PhD, Ryan P. Morton, MD, Michael R. Levitt, MD, and \\ Fangyi Zhang, MD
}

Department of Neurological Surgery, University of Washington School of Medicine, Seattle, Washington

\begin{abstract}
Intracranial hypotension is a rare condition caused by spontaneous or iatrogenic CSF leaks that alter normal CSF dynamics. Symptoms range from mild headaches to transtentorial herniation, coma, and death. Duret hemorrhages have been reported to occur in some patients with this condition and are traditionally believed to be associated with a poor neurological outcome. A 73-year-old man with a remote history of spinal fusion presented with syncope and was found to have small subdural hematomas on head CT studies. He was managed nonoperatively and discharged with a Glasgow Coma Scale score of 15 , only to return 3 days later with obtundation, fixed downward gaze, anisocoria, and absent cranial nerve reflexes. A CT scan showed Duret hemorrhages and subtle enlargement of the subdural hematomas, though the hematomas remained too small to account for his poor clinical condition. Magnetic resonance imaging of the spine revealed a large lumbar pseudomeningocele in the area of prior fusion. His condition dramatically improved when he was placed in the Trendelenburg position and underwent repair of the pseudomeningocele. He was kept flat for 7 days and was ultimately discharged in good condition. On long-term follow-up, his only identifiable deficit was diplopia due to an internuclear ophthalmoplegia. Intracranial hypotension is a rare condition that can cause profound morbidity, including tonsillar herniation and brainstem hemorrhage. With proper identification and treatment of the CSF leak, patients can make functional recoveries.
\end{abstract}

http://thejns.org/doi/abs/10.3171/2015.6.SPINE1521

KEY WORDS intracranial hypotension; Duret hemorrhage; coma; lumbar spine

$\mathrm{I}$ NTRACRANIAL hypotension is a rare condition ( 5 cases per 100,000 persons $)^{5}$ resulting from the leakage of cerebrospinal fluid (CSF) through a spinal dural defect, which deranges the normal CSF hydrodynamics, typically resulting in orthostatic headaches. ${ }^{11}$ Headache severity can range from mild to debilitating. Other nonspecific symptoms include neck pain, diplopia, nausea, vomiting, hearing loss, and tinnitus. ${ }^{4,8,17,18,23,31}$ In rare cases, cranial nerve palsies, stupor, and coma can occur. 2,3,5,10,12,17,23

Symptoms arise from decreased brain buoyancy due to diminished CSF volume, which allows the brain to sag. ${ }^{3,23}$ In severe cases, cortical bridging veins can rupture and result in subdural hematomas, a common confounding radiographic finding in these patients..$^{23,27}$
Intracranial hypotension can be either spontaneous or iatrogenic. In spontaneous cases, the CSF leak most commonly results from dural defects along nerve roots. 5,23 Patients with connective tissue disorders may be predisposed to such spontaneous rents. ${ }^{1,26}$ Iatrogenic causes of intracranial hypotension include procedures such as spinal anesthesia, lumbar puncture, and spinal surgery. $12,27,30$ Symptom onset quickly follows the inciting procedure in most cases. Here, we describe a patient with a history of multiple spinal surgeries who presented with subdural hematomas and Duret hemorrhages 9 months after lumbar spinal surgery..$^{10}$ Despite his grave state and the presence of Duret hemorrhages at presentation, he recovered well after intervention. 


\section{Case Report}

History

A 73-year-old man with a history of multiple prior lumbar spinal surgeries presented with confusion after a syncopal ground-level fall. Head CT demonstrated bilateral thin subdural hematomas without significant mass effect (Fig. 1), which remained stable on a follow-up CT scan. His condition rapidly improved to a Glasgow Coma Scale (GCS) score of 15, and he was discharged in good condition after a negative syncope workup and 24 hours of observation. Three days later, he presented again after a sudden collapse.

\section{Physical Examination and Clinical Workup}

The patient was hypertensive $(198 / 114 \mathrm{~mm} \mathrm{Hg})$, tachycardic, unresponsive, and posturing with a GCS score of 5. His gaze was fixed in a downward position with asymmetrical pupils. Cough and gag reflexes were absent. Head CT demonstrated slight enlargement of the left subdural hematoma, effacement of the basal cisterns, tonsillar herniation, and Duret hemorrhages in the pons and medulla (Fig. 2). Effacement of the basal cisterns was significantly disproportionate to the thin subdural hematomas.

Urgent MRI of the brain and spine confirmed the Duret hemorrhages seen on $\mathrm{CT}$ and also revealed a large lumbar pseudomeningocele extending through the fascia and into the subcutaneous tissues (Fig. 3) that had not been appreciated on physical examination. The patient's family later confirmed that the spinal fusion 9 months prior to presentation was complicated by an intraoperative CSF leak. He had subsequently developed orthostatic headaches and

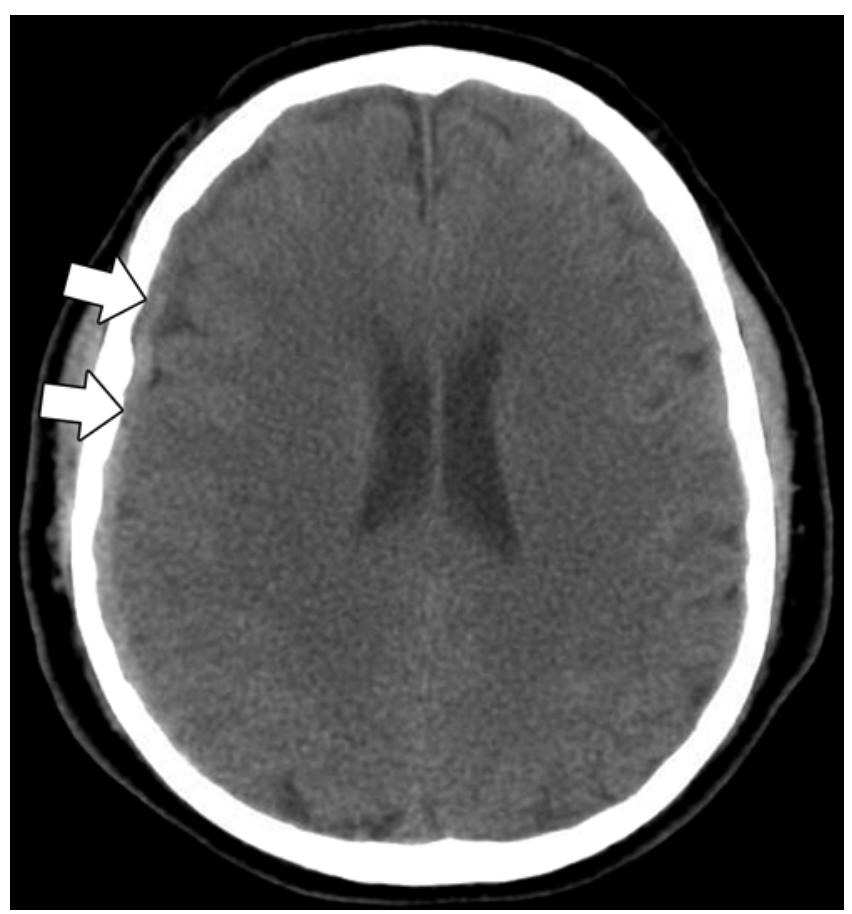

FIG. 1. Head CT obtained on initial presentation, demonstrating thin bilateral subdural hematomas, more prominent on the right (arrows).
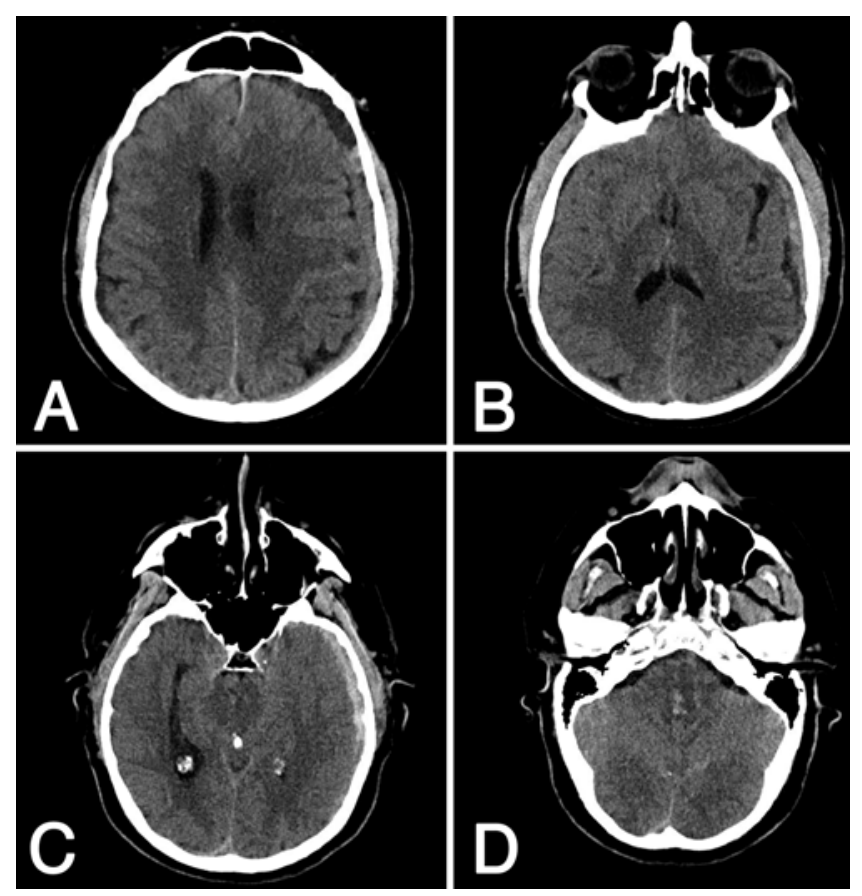

FIG. 2. Head CT obtained after the patient presented a second time, showing enlargement of the left-sided subdural hematoma (A and B) compared with its appearance on a prior scan. There is effacement of the basal cisterns (C), and Duret hemorrhages are evident (D).

had been taken back to the operating room a second time to repair the leak.

\section{Operation}

The patient was immediately placed in the Trendelenburg position and received continuous intravenous fluids. Over the next 12 hours, he began briskly localizing to noxious stimuli and his pupillary reflex returned. Given his rapid clinical improvement, his lumbar pseudomeningocele was explored. In the operating room, a "ball-valve" CSF leak was found at the site of an old dural patch. This
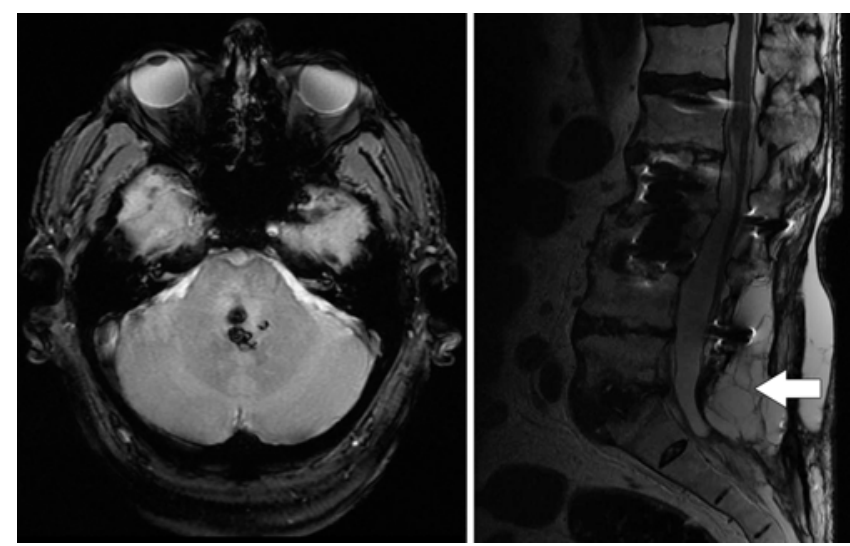

FIG. 3. Brain gradient-echo MR image (left) demonstrating pontine Duret hemorrhages. A large posterior lumbar pseudomeningocele (arrow) can be seen on a sagittal lumbar spine T2-weighted MR image (right). 

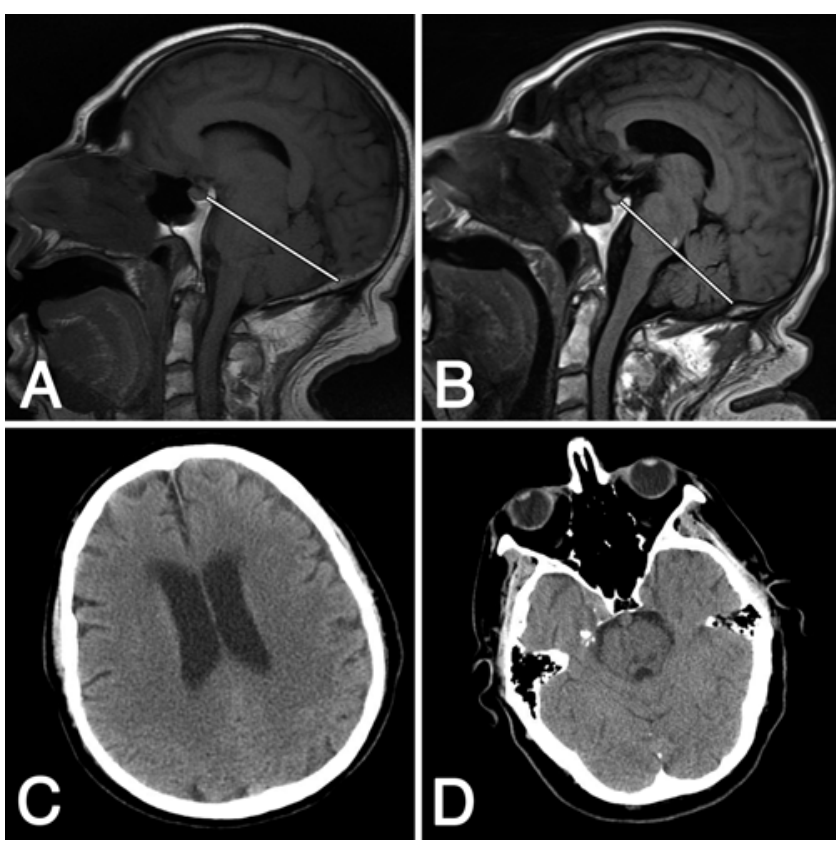

FIG. 4. Sagittal T1-weighted MR images of the craniocervical junction before (A) and after (B) Trendelenburg positioning and lumbar pseudomeningocele repair. The Twining line (drawn from the tuberculum sella to the internal occipital protuberance) is used as reference for the degree of downward herniation. Delayed repeat head CT demonstrated resolution of the subdural hematomas $(\mathbf{C})$ and improvement in the Duret hemorrhages (D).

defect was primarily repaired and reinforced with dural sealant.

\section{Postoperative Course}

Postoperatively, the patient was kept in the Trendelenburg position for 48 hours, at which time he began following commands. The head of the bed remained flat for 7 postoperative days. Repeat MRI demonstrated resolution of the downward herniation (Fig. 4A and B) as measured by the amount of cerebellum and brainstem above the Twining line, which is a line drawn from the tuberculum sella to the internal occipital protuberance. Head CT showed complete resolution of the subdural hematoma and Duret hemorrhages (Fig. 4C and D). The patient was extubated on postoperative Day 8 and subsequently discharged to a skilled nursing facility. His examination was notable for right internuclear ophthalmoplegia and lower-extremity weakness requiring the use of a wheelchair. A gastrostomy tube was placed for dysphagia. At the 9-month follow-up, he had resumed a normal diet and was ambulating without assistive devices. His only significant neurological deficit was a persistent internuclear ophthalmoplegia causing mild diplopia on right lateral gaze.

\section{Discussion}

Patients whose clinical history is concerning for intracranial hypotension should undergo a thorough workup if the diagnosis is unclear. Magnetic resonance imaging of the brain with and without contrast can demonstrate subdural hygromas or hematomas, pachymeningeal enhancement, venous engorgement, pituitary hyperemia, and downward displacement of the brain.7,16,23,24 Myelography can help to identify the site of spinal fluid leak, and spinal MRI can also show engorged venous structures, dural enhancement, or extradural CSF collections. ${ }^{15,19,23,25}$ Lumbar puncture, when performed, typically shows low opening pressures and can demonstrate an elevated lymphocyte count. ${ }^{20,23}$ Spontaneous leaks and those that occur following lumbar puncture can be adequately treated with bed rest, hydration, and caffeine, though autologous blood patches are often required. ${ }^{23}$ Operative repair is occasionally needed, particularly when the leak is the result of a surgical procedure. ${ }^{12,23}$ Generally, the prognosis is favorable. $^{23}$

Severe intracranial hypotension causing coma and herniation is a rare complication of spinal surgery. ${ }^{27,30}$ Previous reports suggest that these cases occur shortly after spinal procedures. Loya and colleagues reported 1 case of delayed intracranial hypotension occurring 2 months following lumbar puncture. ${ }^{12}$ The current case is unique because of the significant delay (9 months) between lumbar surgery and presentation, as well as the degree of neurological recovery despite the poor initial examination and the finding of brainstem hemorrhages, an extremely poor prognostic indicator.

It is not known why this patient experienced such rapid deterioration so long after the initial repair. Most likely, he had a contained, asymptomatic pseudomeningocele that expanded in a delayed fashion. Indeed, symptomatic pseudomeningocele occurs at a rate of $0.8 \%-2 \%$ following lumbar spine surgery, ${ }^{13,29}$ though the rate of asymptomatic collections is probably much higher, particularly among those with known intraoperative durotomies. ${ }^{6,14,33,34}$ For reasons that are not clear, this pseudomeningocele probably expanded into the adjacent soft tissues, perhaps because of tenuous wound healing related to his multiple prior surgeries or perhaps because of the cumulative effect of CSF pulsations against the soft tissues over many months. Whatever the cause, the thecal sac drained fairly rapidly, leading to intracranial hypotension and the patient's abrupt decline. A slow, continuous leak is an alternative explanation, but intuitively such a leak should lead to an insidious progression of symptoms and not the rapid worsening experienced by our patient.

After admission, the patient demonstrated marked clinical improvement in the Trendelenburg position. Normally, the buoyancy provided by CSF counteracts the downward pull of gravity on the brain, but the loss of spinal fluid in intracranial hypotension causes the brain to sag against the meninges, leading to orthostatic headaches..$^{3,11,23}$ In severe cases, nervous and vasculature structures are also placed under tension, which can cause disruption of neurological function and hemorrhage. ${ }^{22,23}$ If left untreated, transtentorial and/or tonsillar herniation can occur. We attribute our patient's betterment to the removal of tension from the meninges, neural structures, and vasculature, which were no longer working to counteract gravity. In addition, the brainstem and cerebellum were no longer being forced downward into the foramen magnum, thus reversing the medullary compression from 
tonsillar herniation. Hydration with intravenous fluids and repair of the dural leak allowed for reaccumulation of CSF volume and an eventual return to normal intrathecal hydrodynamics.

Whereas subdural collections are common in intracranial hypotension, Duret hemorrhages as a consequence of intracranial hypotension are very rare. These hemorrhages are thought to occur during transtentorial herniation as perforating branches of the basilar artery are disrupted. We are aware of only 2 other reported cases of Duret hemorrhage from intracranial hypotension. In 1 spontaneous case, the outcome was poor; ${ }^{2}$ in the other case, which was caused by lumbar puncture, the patient made a good recovery. ${ }^{32}$

The traumatic brain injury literature contains several reports of patients making a good recovery (Glasgow Outcome Scale score $\geq 4$ ) from Duret hemorrhage., ${ }^{912,28}$ As in the current case, these reported lesions were located in the central pons, which may have limited damage to the reticular formations located in the dorsal pontine tegmentum. ${ }^{9}$ This location is likely to affect the lateral gaze centers, the medial longitudinal fasciculi, and/or the oculomotor nuclei, which may explain the diplopia observed in those who recover. ${ }^{21}$

The present case illustrates the importance of accurately identifying and treating intracranial hypotension, as even the sickest patients with this syndrome can make marked recoveries despite poor neurological examinations and discouraging findings on brain imaging. It also demonstrates the difficulty in diagnosis, as many of the clinical characteristics and imaging findings are nonspecific and disproportionate to the patient's neurological condition. Thorough history taking and a careful review of radiological studies can narrow the otherwise broad differential diagnosis, guide proper management, and lead to good clinical outcomes from this rare condition.

\section{References}

1. Albayram S, Ulu MO, Isler C: Intracranial hypotension. J Neurosurg 109:362, 2008 (Letter)

2. Chi NF, Wang SJ, Lirng JF, Fuh JL: Transtentorial herniation with cerebral infarction and Duret haemorrhage in a patient with spontaneous intracranial hypotension. Cephalalgia 27:279-282, 2007

3. Couch JR: Spontaneous intracranial hypotension: the syndrome and its complications. Curr Treat Options Neurol 10:3-11, 2008

4. Ferrante E, Savino A, Brioschi A, Marazzi R, Donato MF, Riva M: Transient oculomotor cranial nerves palsy in spontaneous intracranial hypotension. J Neurosurg Sci 42:177180, 1998

5. Gordon N: Spontaneous intracranial hypotension. Dev Med Child Neurol 51:932-935, 2009

6. Hawk MW, Kim KD: Review of spinal pseudomeningoceles and cerebrospinal fluid fistulas. Neurosurg Focus 9(1):e5, 2000

7. Holmes JM: Intracranial hypotension associated with subdural haematoma. BMJ 1:1363-1366, 1953

8. Horton JC, Fishman RA: Neurovisual findings in the syndrome of spontaneous intracranial hypotension from dural cerebrospinal fluid leak. Ophthalmology 101:244-251, 1994

9. Ishizaka S, Shimizu T, Ryu N: Dramatic recovery after severe descending transtentorial herniation-induced Duret haemorrhage: a case report and review of literature. Brain Inj 28:374-377, 2014

10. Kashmere JL, Jacka MJ, Emery D, Gross DW: Reversible coma: a rare presentation of spontaneous intracranial hypotension. Can J Neurol Sci 31:565-568, 2004

11. Leriche R: De l'hypotension du liquide céphalorachidien dans certaines fractures de la base du crâne et de son traitment par l'injection de serum sous la peau. Lyon Chir 17:638, 1920

12. Loya JJ, Mindea SA, Yu H, Venkatasubramanian C, Chang SD, Burns TC: Intracranial hypotension producing reversible coma: a systematic review, including three new cases. J Neurosurg 117:615-628, 2012

13. Mayfield FH: Complications of laminectomy. Clin Neurosurg 23:435-439, 1976

14. McMahon P, Dididze M, Levi AD: Incidental durotomy after spinal surgery: a prospective study in an academic institution. J Neurosurg Spine 17:30-36, 2012

15. Moayeri NN, Henson JW, Schaefer PW, Zervas NT: Spinal dural enhancement on magnetic resonance imaging associated with spontaneous intracranial hypotension. Report of three cases and review of the literature. J Neurosurg 88:912-918, 1998

16. Pannullo SC, Reich JB, Krol G, Deck MD, Posner JB: MRI changes in intracranial hypotension. Neurology 43:919-926, 1993

17. Pleasure SJ, Abosch A, Friedman J, Ko NU, Barbaro N, Dillon W, et al: Spontaneous intracranial hypotension resulting in stupor caused by diencephalic compression. Neurology 50:1854-1857, 1998

18. Portier F, de Minteguiaga C, Racy E, Huy PT, Herman P: Spontaneous intracranial hypotension: a rare cause of labyrinthine hydrops. Ann Otol Rhinol Laryngol 111:817-820, 2002

19. Rabin BM, Roychowdhury S, Meyer JR, Cohen BA, LaPat KD, Russell EJ: Spontaneous intracranial hypotension: spinal MR findings. AJNR Am J Neuroradiol 19:1034-1039, 1998

20. Rando TA, Fishman RA: Spontaneous intracranial hypotension: report of two cases and review of the literature. Neurology 42:481-487, 1992

21. Rouhl RP, Postma AA: Teaching NeuroImages: Duret hemorrhage due to bilateral subdural hematomas causing internuclear ophthalmoplegia. Neurology 79:e101, 2012

22. Royon V, Rabehenoina C, Tourrel F, Compère V, Dureuil B: Remote cerebellar hemorrhage as an early and potentially lethal complication of a discal lumbar herniation surgery. Ann Fr Anesth Reanim 33:e19-e21, 2014

23. Schievink WI: Spontaneous spinal cerebrospinal fluid leaks and intracranial hypotension. JAMA 295:2286-2296, 2006

24. Schievink WI, Maya MM, Moser FG, Tourje J: Spectrum of subdural fluid collections in spontaneous intracranial hypotension. J Neurosurg 103:608-613, 2005

25. Schievink WI, Meyer FB, Atkinson JL, Mokri B: Spontaneous spinal cerebrospinal fluid leaks and intracranial hypotension. J Neurosurg 84:598-605, 1996

26. Schievink WI, Reimer R, Folger WN: Surgical treatment of spontaneous intracranial hypotension associated with a spinal arachnoid diverticulum. Case report. J Neurosurg 80:736-739, 1994

27. Sciubba DM, Kretzer RM, Wang PP: Acute intracranial subdural hematoma following a lumbar CSF leak caused by spine surgery. Spine (Phila Pa 1976) 30:E730-E732, 2005

28. Stiver SI, Gean AD, Manley GT: Survival with good outcome after cerebral herniation and Duret hemorrhage caused by traumatic brain injury. J Neurosurg 110:1242-1246, 2009

29. Teplick JG, Peyster RG, Teplick SK, Goodman LR, Haskin ME: CT Identification of postlaminectomy pseudomeningocele. AJR Am J Roentgenol 140:1203-1206, 1983

30. Thomas G, Jayaram H, Cudlip S, Powell M: Supratentorial and infratentorial intraparenchymal hemorrhage secondary 
to intracranial CSF hypotension following spinal surgery. Spine (Phila Pa 1976) 27:E410-E412, 2002

31. Warner GT: Spontaneous intracranial hypotension causing a partial third cranial nerve palsy: a novel observation. Cephalalgia 22:822-823, 2002

32. Yuan X, Zhao H, Zhao C, Zhao H, Xiao H, Sun G, et al: Duret hemorrhage after lumbar drainage. J Craniofac Surg 25:1551-1552, 2014

33. Zide BM, Epstein FJ, Wisoff J: Optimal wound closure after tethered cord correction. Technical note. J Neurosurg 74:673-676, 1991

34. Zide BM, Wisoff JH, Epstein FJ: Closure of extensive and complicated laminectomy wounds. Operative technique. J Neurosurg 67:59-64, 1987

\section{Disclosures}

The authors report no conflict of interest concerning the materi- als or methods used in this study or the findings specified in this paper.

\section{Author Contributions}

Conception and design: all authors. Acquisition of data: all authors. Analysis and interpretation of data: all authors. Drafting the article: Bonow, Bales, Morton. Critically revising the article: Bonow, Morton, Levitt. Reviewed submitted version of manuscript: Bonow, Morton, Zhang. Approved the final version of the manuscript on behalf of all authors: Bonow. Study supervision: Levitt, Zhang.

\section{Correspondence}

Robert H. Bonow, Department of Neurological Surgery, University of Washington School of Medicine, 325 9th Ave., Box 359924, Seattle, WA 98104. email: rbonow@u.washington. edu. 